\title{
Sternal force distribution during median sternotomy retraction
}

\author{
Philipp Aigner, MSc, ${ }^{\text {a,b }}$ Farsad Eskandary, MD, ${ }^{c}$ Thomas Schlöglhofer, BSc, ${ }^{\text {a,b,c }}{ }^{\text {Roman Gottardi, MD, }}$ \\ Klaus Aumayr, MD, ${ }^{d}$ Günther Laufer, MD, ${ }^{\mathrm{b}, \mathrm{c}}$ and Heinrich Schima, $\mathrm{PhD}^{\mathrm{a}, \mathrm{b}, \mathrm{c}}$
}

Background: Median sternotomy is the access of choice in cardiac surgery. Sternal retractors exert significant forces on the thoracic cage and might cause considerable damage. The aim of this study was to determine the effects of retractor shape on local force distribution to obtain criteria for retractor design.

\begin{abstract}
Methods: Two types of sternal retractors (straight [SSR] and curved [CSR]) were equipped with force sensors. Force distribution, total force, and displacement were recorded to a spread width of $10 \mathrm{~cm}$ in 18 corpses (11 males and 7 females; age, $62 \pm 12$ years). Both retractors were used in alternating sequence in 4 iterations in every corpse. Data were compared with respect to the different retractor blade shapes.
\end{abstract}

Results: Maximum total forces for full retraction of both retractors resulted in $349.4 \pm 77.9 \mathrm{~N}$. Force distribution during the first retraction for the cranial/median/caudal part of the sternum was $101.5 \pm 43.9 / 29.1 \pm 33.9 / 63.0 \pm 31.4 \mathrm{~N}$ for the SSR and $38.7 \pm 41.3 / 80.9 \pm 64.5 / 34.0 \pm 25.8 \mathrm{~N}$ for the CSR, respectively. During the 4 spreading cycles, the average force decreased from $224.6 \pm 61.3 \mathrm{~N}$ in the first to $110.8 \pm 39.8 \mathrm{~N}$ in the fourth iteration. The mean total force for the first retraction revealed $226.4 \pm 71.9 \mathrm{~N}$ for the CSR and $222.8 \pm 52.9 \mathrm{~N}$ for the SSR.

Conclusions: The shape of sternal retractors considerably influences the force distribution on the sternal incision. In the SSR, forces on the cranial and caudal sternum are significantly higher than in the median section, whereas in the CSR, forces in the median section are highest. (J Thorac Cardiovasc Surg 2013;146:1381-6)

\begin{abstract}
Median sternotomy is the access of choice for most cardiac surgical procedures when minimal invasive approaches seem contraindicated. ${ }^{1}$ To achieve optimal surgical sight, sternal retractors that differ in form, size, and retractor blade shape are used. The retractor blades exert significant mechanical forces on the surrounding tissue. These local forces can cause reversible and irreversible tissue damage in direct correlation to their magnitude. Disruptive forces occur in the area of the sternotomy itself and in the costovertebral joints and contribute to the development of postthoracotomy pain syndrome., ${ }^{2,3}$ The postoperative course may be further significantly complicated by the occurrence of sternal wound healing disorders or deep sternal wound infections, sometimes resulting in lifethreatening mediastinitis. The incidence of delayed wound healing and sternal infections $(0.4 \%-7 \%)$ is considerable..$^{4-8}$ These complications can lead to prolonged hospital stay and dramatic increase in costs for health care
\end{abstract}

\footnotetext{
From the Center for Medical Physics and Biomedical Engineering ${ }^{\mathrm{a}}$ and the Departments of Cardiac Surgery ${ }^{\mathrm{c}}$ and Pathology, ${ }^{\mathrm{d}}$ Medical University of Vienna, Vienna, Austria; and the Ludwig Boltzmann Cluster for Cardiovascular Research, ${ }^{\text {b }}$ Vienna, Austria.

Disclosures: Authors have nothing to disclose with regard to commercial support. Received for publication March 8, 2013; revisions received July 12, 2013; accepted for publication July 26, 2013; available ahead of print Sept 26, 2013.

Address for reprints: Philipp Aigner, MSc, Center for Medical Physics and Biomedical Engineering, Medical University Vienna, AKH-4L, Währinger Gürtel 18, A-1090 Vienna, Austria (E-mail: philipp.aigner@meduniwien.ac.at). $0022-5223 / \$ 36.00$

Copyright $(2013$ by The American Association for Thoracic Surgery http://dx.doi.org/10.1016/j.jtcvs.2013.07.075
}

providers, ${ }^{9,10}$ with a considerable mortality rate between $14 \%$ and $50 \%{ }^{4-8}$ Moreover, sternal retraction can cause a lesion of the brachial plexus. ${ }^{11-16}$

Because of the impact of local compression trauma, a minimization of local forces exerted by the retractor is of importance. Animal studies in sheep showed that a force monitoring setup and reduced retraction speed could provide surgeons with the equivalent exposure sight of the inner organs, whereas peak forces and tissue damage are significantly reduced. ${ }^{2,17}$ In the literature, there are no data available for humans and we hypothesize that the shape of the sternal retractor influences the force distribution during retraction. The wide variety of sternal retractor types with different sizes and numbers of blades available on the market (eg, Dubost, Cooley, Morse, McCarthy, Finochietto, Ankeney) does not allow investigations that include all types of retractors. Therefore, the aim of this study was to measure the force distribution in 2 sternal retractors used in our institution to detect eventual peak forces and obtain information for optimal retractor design.

\section{METHODS}

Two types of sternal retractors, a straight retractor (SSR) (MTEZ 424 735; Heintel GmbH, Vienna, Austria) and a curved retractor (CSR) (Dubost Thoracic Retractor DC30000-00; Delacroix-Chevalier, Paris, France), were equipped with FlexiForce single-element foil load sensors (A201-100 lb/445 N; Tekscan Inc, South Boston, Mass) to measure the force distribution over the retractor blades. Proper sensor load distribution was guaranteed by a mechanical plate that connected and guided 2 pistons to directly push on 2 sensors (Figure 1). 


\section{Abbreviations and Acronyms \\ $\mathrm{CSR}=$ curved sternal retractor \\ $\mathrm{SSR}=$ straight sternal retractor}

The blade of the mobile arm of the SSR (length, $6.5 \mathrm{~cm}$; width, $4.5 \mathrm{~cm}$ ) was equipped with an array of 2 times 4 sensors, and the mobile arm of the CSR (length, $9.7 \mathrm{~cm}$; width, $4.8 \mathrm{~cm}$; curvature radius, $\approx 21 \mathrm{~cm}$ ) was equipped with an array of 2 times 5 sensors. Finally, the sum of the single sensor forces yielded the total force.

The mobile retractor arm was coupled with a potentiometer for distance measurement (Figure 2), and the instrumented blades of the retractors were covered in plastic foil to prevent fluid penetration.

The sensor signals were recorded by a data acquisition card (NI DAQCard-6036E; National Instruments, Austin, Tex) and DASYLab 11.0 Software (National Instruments, Austin, Tex), with a sampling rate of $10 \mathrm{~Hz}$. Evaluation of the data was done in Matlab (R2008; The MathWorks Inc, Natick, Mass).

The median sternotomy study was approved by the local university review board and performed on 21 corpses. Exclusion criteria were known osteoporosis, previous sternotomies, and thorax malformations. Because of the high rate of rib and sternum fractures after cardiopulmonary resuscitation, ${ }^{18}$ corpses after unsuccessful resuscitation were not included in the study.

First, the skin incision in the midline of the chest from the jugulum to the xiphoid was made at the corpse lying in supine position. After opening the skin, the subcutaneous tissue was divided down to the sternum. Then, the sternum was cut with an oscillating saw along the long axis into 2 halves.

Because of the limited availability of suitable corpses at the department of pathology, we also included corpses with signs of rigor mortis that were classified by the pathologist by bending the elbow joint.

Within the first 3 pilot tests, the positioning of the retractors and the reproducibility of the application technique were optimized. Then, corpses of 18 patients were included in the study and divided into 2 groups. Both retractors were used in every specimen to compensate for the effects of the initial retraction and to compensate for individual differences. As retraction displacement, a width of $10 \mathrm{~cm}$ was used and 4 retractions were done on each corpse. In the operating room, higher retraction distances may occur, but the chosen displacement value should allow better comparison over the retraction iterations. In group A $\left(n_{\mathrm{A}}=9\right)$, the first retraction was performed with the SSR, followed by 2 retractions with the CSR. The final retraction with the SSR completed the measurements. Within group $B\left(n_{B}=9\right)$, a first retraction was done with the CSR, followed by 2 SSR retractions; finally, the CSR was used again. After each retraction, the retractor was removed and the distances between the sternum at the sternal body and at the manubrium were measured.

All retractions were performed at a similar pace because of the known influences of retraction speed on force development. ${ }^{2,17}$ After measurements, routine autopsies were continued.

Before parametric statistical analysis, data were critically reviewed regarding variance homogeneity and normal distribution. Total force of the first measurement was analyzed with a 2-factorial analysis of variance (group of bodies [straight vs curved] $\times$ sex [male vs female] as independent variables). Force values from each sensor of the first measurement of each retractor type were analyzed with a 1 -factorial analysis of variance (4 and 5 sensors, respectively, as independent variables), followed by post hoc Scheffé test. All data are presented as mean and SD. Furthermore, in all tests, the level of significance was set at $P<.05$. Descriptive and inferential statistics $(2$ sided) were calculated with IBM SPSS Statistics 21 (IBM Corp, Armonk, NY).

\section{RESULTS \\ Experimental Data}

Successful median sternotomy completion with a retraction width of $10 \mathrm{~cm}$ was achieved in all 18 corpses. Sex distribution (11 males and 7 females) between groups was as follows: group A, 6 male $(67 \%)$ versus 3 female $(33 \%)$ corpses; group B, 5 male $(54 \%)$ and 4 female $(46 \%)$ corpses. All other demographic data of the corpses of groups A and B are presented in Table 1. Full development of rigor mortis was found in 2 cases, moderate manifestation was found in 4 cases, and no signs of rigor mortis were noticeable in 12 cases. Exemplary total force, retraction displacement, and force-displacement relationship data can be found in Figure 3. Retraction time to $10 \mathrm{~cm}$ was $14.3 \pm 6.2$ seconds.

\section{Force Distribution}

The force distribution over the retractor blades revealed completely different patterns in the 2 types. Whereas, in the SSR, the highest values for the mean force during retraction were found in the cranial, the first sensor pair $(101.5 \pm 43.9 \mathrm{~N})$, followed by the caudal, the fourth pair $(63.0 \pm 31.4 \mathrm{~N})$; the lowest values were registered in the third $(32.4 \pm 27.8 \mathrm{~N})$ and the second $(25.9 \pm 40.5 \mathrm{~N})$ pairs. On the other hand, in the CSR within the first retraction, highest values were found in the middle, the third sensor pair $(80.9 \pm 64.5 \mathrm{~N})$, with a decrease of force to the cranial and caudal pairs (first pair, $39.9 \pm 54.9 \mathrm{~N}$; second pair, $37.5 \pm 24.7 \mathrm{~N}$; fourth pair, $38.0 \pm 25.6 \mathrm{~N}$; fifth pair, $30.1 \pm 27.0 \mathrm{~N}$ ) (Figure 4). The same distributions were discovered in all 4 retractions, at different spread widths $(5,7.5$, and $10 \mathrm{~cm})$, and were independent of sex.

\section{Total Force}

The total mean force for the retraction revealed no significant differences between the SSR and the CSR $(222.8 \pm 52.9 \mathrm{~N}$ vs $226.4 \pm 71.9 \mathrm{~N})$. During the first retraction, no significant differences $(P=.755)$ between groups $\mathrm{A}$ and $\mathrm{B}$ were found in the mean and peak forces. Nevertheless, the comparison of the mean total force showed significant sex differences. In the first retraction, in male specimens, $256.2 \pm 43.3 \mathrm{~N}$ was found; and in female specimens, only $174.9 \pm 52.9 \mathrm{~N}$ was found $(P=.004)$.

The force applied to reach full retraction of $10 \mathrm{~cm}$ was $290.1 \pm 91.1 \mathrm{~N}$ for the first retraction. In the following 3 retractions, this force decreased significantly to $250.2 \pm 84.6 \mathrm{~N}, 235.3 \pm 82.9 \mathrm{~N}$, and $208.8 \pm 64.2 \mathrm{~N}$ $(P<.001)$. The maximum force for full retraction was $493.6 \mathrm{~N}$, whereas the smallest maximum force was $159.0 \mathrm{~N}$.

\section{Rigor Mortis}

Analyzing eventual differences between corpses with and without rigor mortis, it became apparent that in the presence 

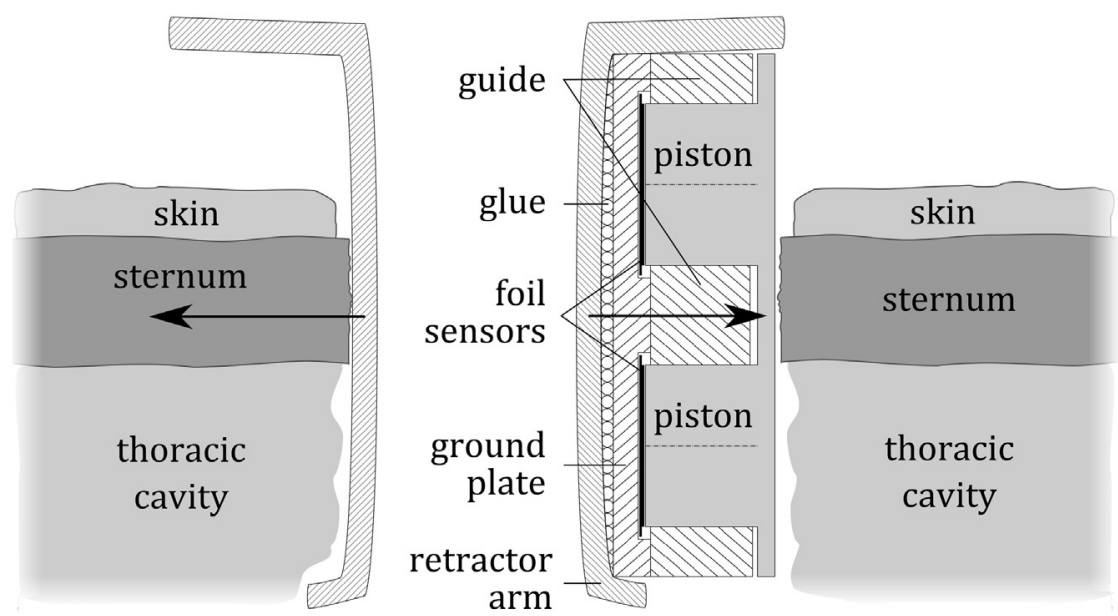

FIGURE 1. Schematic of the tilting protection setup with a plate for an even load distribution on each foil sensor.

of partial and full developed rigor mortis the uppermost (cranial) and lowest (caudal) sensors showed increased forces compared with the non rigor corpses (CSR: cranial, $2.3 \times$; caudal, $3.7 \times$; SSR, $1.7 \times$ cranial and caudal). In corpses with partial or full developed rigor mortis, a higher total force for full retraction of $10 \mathrm{~cm}(329.8 \pm 56.8 \mathrm{~N}$; $\mathrm{n}=6)$ than in the no rigor corpses $(270.3 \pm 100.3 \mathrm{~N}$; $\mathrm{n}=12$ ) was found. However, this influence did not change the overall findings.

\section{Other Observations}

In one corpse, a retraction-induced fracture was observed during the second retraction (Figure 3). At a distance of $9.4 \mathrm{~cm}$, a cracking sound simultaneously accompanied by a decrease in total force $(-51.6 \mathrm{~N})$ caused by a decrease in the most cranial sensor pair was monitored. The first retraction was done with the CSR, but the presumable fracture occurred during the second retraction with the SSR.

\section{DISCUSSION}

Investigations of forces applied on human sternum during median sternotomy are not available in the literature. Therefore, 2 basic designs of sternal retractors were investigated in this corpse study to gather first results. A human corpse model was used because of its ease of application and advantages (eg, repeatability, well-defined conditions, and controlled speed of retraction) compared with a clinical application.

Complications after median sternotomy are a wellrecognized problem, and several attempts (eg, ministernotomy, partial sternotomy, and lateral thoracotomy) have been made to avoid (complete) splitting of the sternum. ${ }^{19-22}$ Nevertheless, $37 \%$ of the patients experience chronic pain that is related to the sternotomy itself for more than 6 months after operation. ${ }^{23}$ Even 1 year after surgery, poststernotomy pain was found in $14 \%$ to $51 \%$ of the patients. ${ }^{24,25}$ These complications are related to mechanical destruction of biologic structures and, most probably, peak retraction forces cause bone fracture and average retraction forces are responsible for possible nerve damages. ${ }^{17}$ Fractures of the first rib, the second rib, or the costotransverse articulation are documented, with an incidence of $3.6 \%$ to $16 \%$ in patients undergoing median sternotomy often attributed to excessive retraction ${ }^{11,26-28}$; however, they are frequently occult and not diagnosable on routine chest X-ray film. ${ }^{12,18}$ Baisden and colleagues $^{12}$ revealed occult rib fractures of mainly the upper ribs in even $50 \%$ to $67 \%$ of sternotomy patients with bone scans. The higher loads on the first ribs because of the retraction are completely supported by our results in the SSR.
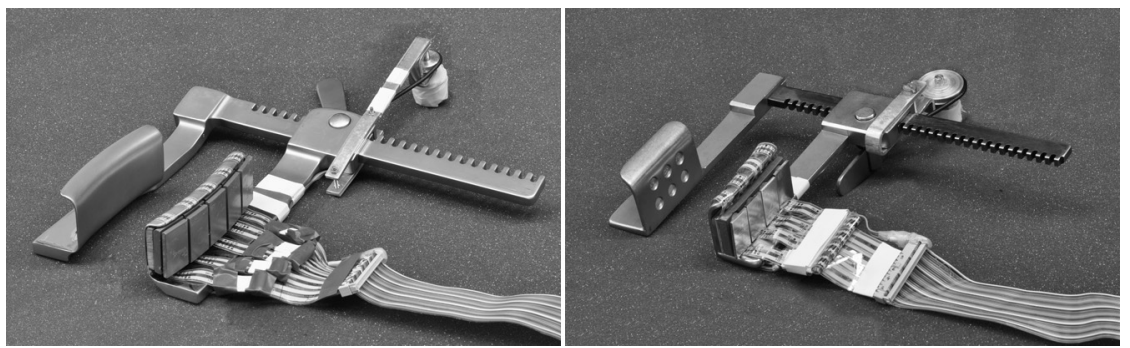

FIGURE 2. Final instrumented retractors (left, curved sternal retractor; right, straight sternal retractor) for force measurement before wrapping in plastic foil. 
TABLE 1. Demographics

\begin{tabular}{lccc}
\hline & Minimum & Maximum & Mean \\
\hline Age, y & 31 & 75 & $61.8 \pm 11.8$ \\
Weight, kg & 38 & 120 & $75.5 \pm 19.9$ \\
Size, cm & 160 & 191 & $172 \pm 7$ \\
Axilla-axilla distance, cm & 28 & 45 & $36 \pm 4$ \\
Postmortem time, h & 6.1 & 78.6 & $27.5 \pm 20.8$ \\
Manubrium thickness, cm & 0.8 & 2.0 & $1.3 \pm 0.3$ \\
Sternal body thickness, cm & 0.7 & 1.6 & $1.1 \pm 0.3$ \\
Sternum length, cm & 16 & 25 & $21 \pm 3$ \\
Depth of thorax, cm & 17 & 25 & $20 \pm 3$ \\
\hline
\end{tabular}

The highest forces were applied on the upper end of the retractor blades at the manubrium, where the first ribs attach, and a documented fracture occurred during the use of the SSR. In that corpse, the first retraction was performed with the CSR to $10 \mathrm{~cm}$; the fracture did not occur until the second retraction with the SSR. The SSR applied increased forces to the upper part of the sternum and caused a fracture.
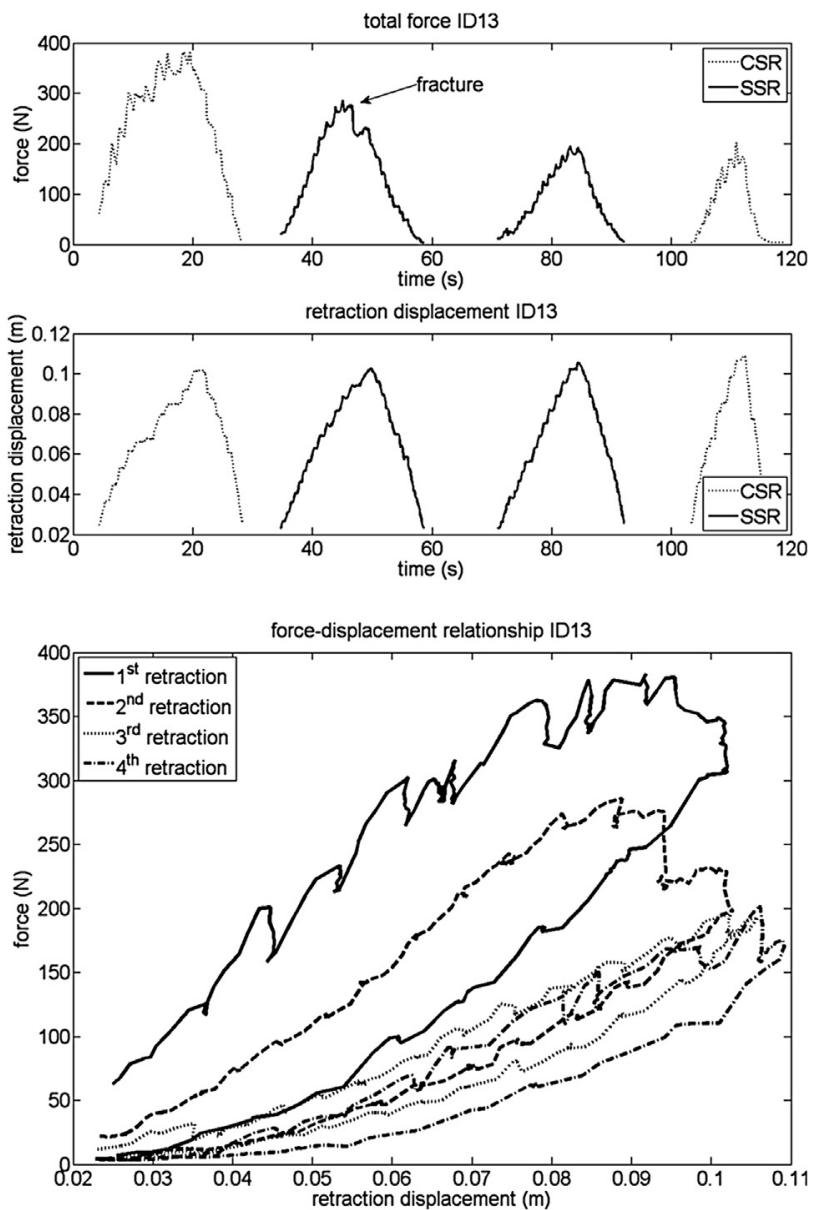

FIGURE 3. Exemplary force and retraction displacement (top) and forcedisplacement relationship (bottom) in corpse ID13. The arrow marks a decrease in total force due to an unlocated fracture. $C S R$, Curved sternal retractor; $S S R$, straight sternal retractor.
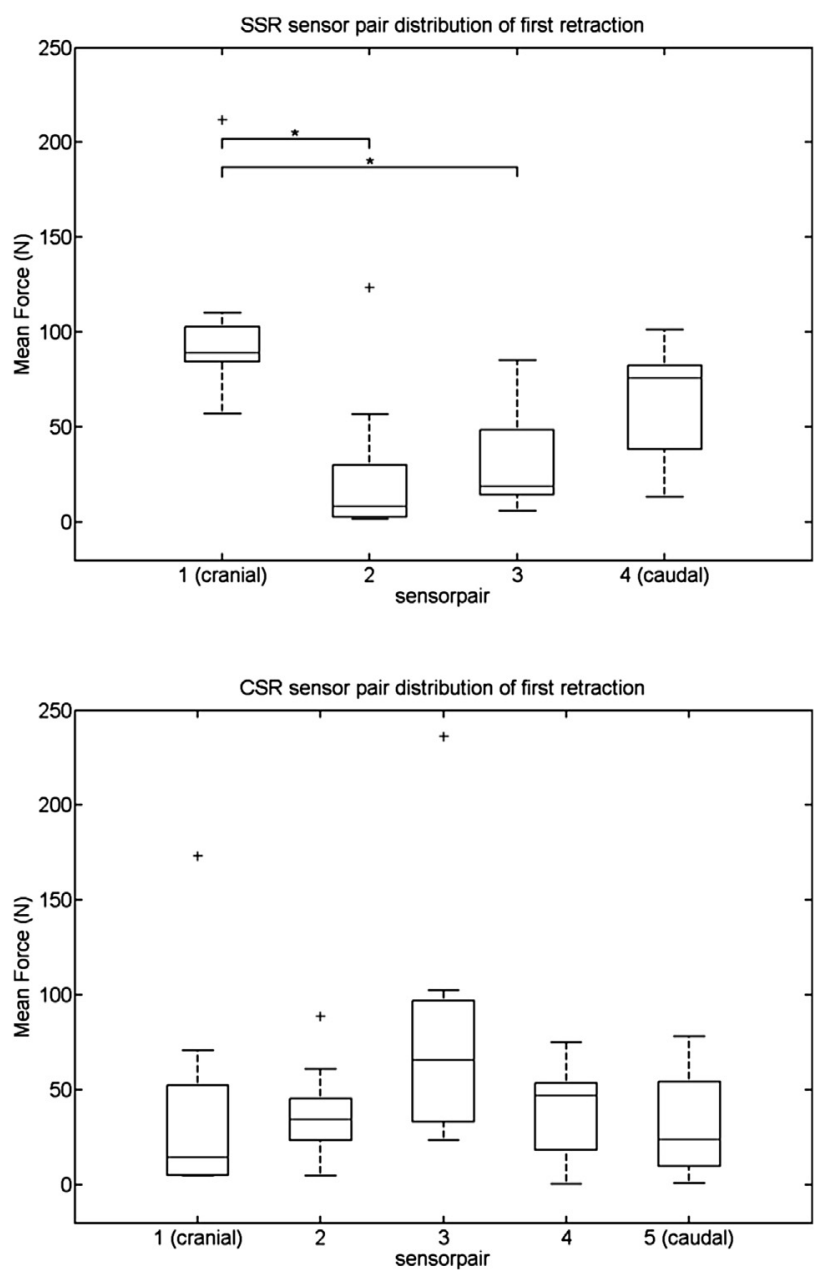

FIGURE 4. Different force distribution patterns over the sensor pairs in the straight sternal retractor (SSR; top) and curved sternal retractor $(C S R ;$ bottom $)$.

These highest forces on the upper structures are due to the fact that the circumference of the upper rib is smallest, but full retraction distance is applied to this structure with straight-blade geometry in the SSR.

General suggested methods to minimize rib fractures and brachial plexus injuries are a reduced retraction distance and traction adapted to the patient size and different patient positioning. ${ }^{3,12,26,29}$ Further literature ${ }^{28,30-32}$ and our results of the SSR measurements suggest a positioning of the SSR blades in a more caudal position, if surgically possible. That would reduce the forces on the cranial thoracic structures with smaller rib curvatures and minimize fractures at the manubrium or the first ribs. The incidence of rib fractures can be reduced if sternal retractors are placed at a more caudal position. ${ }^{14,26,33}$ Nevertheless, this could lead to high local forces in the region of the relatively poor vascularized xiphoid structure and might result in microperfusion dysfunction. This is relevant because incipient sternal dehiscence is often related to the distal part. ${ }^{34}$ 
In contrast, the force distribution in the CSR was completely different. Because of the curved profile, the sternum touches the retractor first at the middle, and the highest forces in the middle section of the retractor blades result from that geometric fact. Hence, reduced strain on the first ribs and highest forces at the middle part of the curved retractor were found. We assume that a less curved retractor would even result in an equal force distribution over the whole retractor blade. Nonetheless, the CSR can probably help to prevent from fractures of the first and second rib because the maximum applied force occurs more caudal, where the costal arches are bigger and endure that strain easier. In addition, the CSR is approximately 1.5 times longer compared with the SSR and, therefore, was equipped with more sensors. Because of the bigger blades, but the same total force, the force per area (pressure) on the sternum was decreased and probably leads to less compression trauma. This fact would advocate the CSR for clinical application. Nevertheless, its bigger size may not allow its use in small patients.

During cardiac surgery, higher retraction values than the used $10 \mathrm{~cm}$ are reached. Nevertheless, several retractions with higher distances might destroy tissue on a large scale and would not allow investigations with 4 iterations. We investigated the force distribution in each group at different retraction widths and saw no differences in the distribution patterns. Overall, the 4 performed retraction cycles force values were significantly reduced from the first to the second retraction, most probably because of irreversible tissue destruction.

This study was, to our knowledge, the first to investigate the total force and force distribution of different retractor shapes on human sterna. Although Bolotin and colleagues performed force investigations on sheep during lateral thoracotomy ${ }^{17}$ and median sternotomy, ${ }^{2}$ giving details of retraction speed influence, data about force distribution on sternal tissue are not available. The presented data indicate that there are differences between sex in the required total force for retraction. But, in addition, we learned that the distribution is independent of this total force. Measurements were performed on corpses and, of course, it would be advantageous to measure the forces in the operating room itself. However, this would require a resterilizable setup, which does not hinder the operation and does not cause additional risks.

\section{Limitations}

Although a wide variety of different retractor shapes exists, only 2 basic types were investigated within this study because of the limited number of available corpses and to gather first results. Moreover, many of the available corpses did not meet the inclusion criteria and, therefore, corpses with rigor mortis were included. Although an existing rigor mortis influenced, as expected, the force results in the uppermost cranial and lowest caudal sensor, it did not change the findings of the study.

\section{CONCLUSIONS}

Summing up the study reveals major differences in the local force distribution of 2 classic sternal retractors. The SSR seems to be more prone to result in fracture of the first rib or costotransverse articulation because of the highest forces on the most upper part, whereas the curvature of the CSR leads to highest forces to the middle sensors. Furthermore, the highest forces are smoother distributed in the CSR because of the bending and do not meet an edge where local peak forces are present, as found on the upper and lower ends of the SSR. These findings suggest the use of a curved thoracic retractor. Otherwise straight retractors should be used in a more caudal position to reduce the peak forces on the first ribs.

We thank Harald T. Zipko for his advice on statistical analysis and Christoph Haslinger and Ralf Willimayer from the Department of Biomedical Engineering, University of Applied Sciences Technikum Vienna, for the technical assistance.

\section{References}

1. Farhat F, Metton O, Jegaden O. Benefits and complications of total sternotomy and ministernotomy in cardiac surgery. Surg Technol Int. 2004;13:199-205.

2. Bolotin G, Buckner GD, Campbell NB, Kocherginsky M, Raman J, Jeevanandam V, et al. Tissue-disruptive forces during median sternotomy. Heart Surg Forum. 2007; 10:487-92.

3. Jellish WS, Blakeman B, Warf P, Slogoff S. Somatosensory evoked potential monitoring used to compare the effect of three asymmetric sternal retractors on brachial plexus function. Anesth Analg. 1999;88:292.

4. Sjögren J, Malmsjö M, Gustafsson R, Ingemansson R. Poststernotomy mediastinitis: a review of conventional surgical treatments, vacuum-assisted closure therapy and presentation of the Lund University Hospital mediastinitis algorithm. Eur J Cardiothorac Surg. 2006;30:898-905.

5. Blanchard A, Hurni M, Ruchat P, Stumpe F, Fischer A, Sadeghi H. Incidence of deep and superficial sternal infection after open heart surgery: a ten years retrospective study from 1981 to 1991. Eur J Cardiothorac Surg. 1995;9:153-7.

6. EI Oakley R, Paul E, Wong PS, Yohana A, Magee P, Walesby R, et al Mediastinitis in patients undergoing cardiopulmonary bypass: risk analysis and midterm results. J Cardiovasc Surg (Torino). 1997;38:595-600.

7. EI Gamel A, Yonan NA, Hassan R, Jones MT, Campbell CS, Deiraniya AK, et al. Treatment of mediastinitis: early modified robicsek closure and pectoralis major advancement flaps. Ann Thorac Surg. 1998;65:41-6.

8. Sirch J, Koukal C, Oertel F, Fenchel G, Beyer M. Vakuumversiegelung bei schwerer Sternumosteitis nach herzchirurgischen Eingriffen. Z Herz Thorax Gefäßchir. 1998;12:172-6.

9. Cremer J, Gerber I, Mehler D, Haverich A. Wound infections after heart surgery interventions: a cost analysis [in German]. Langenbecks Arch Chir Suppl Kongressbd. 1997;114:1356-7.

10. Mossad M, Serkey R, Longworth M, Cosgrove MI, Gordon M. Coagulasenegative staphylococcal sternal wound infections after open heart operations. Ann Thorac Surg. 1997;63:395-401.

11. Suzuki S, Kikuchi K, Takagi K, Masuda H, Yoshizu H, Tanaka S, et al. Brachia plexus injury and fracture of the first rib as complications of median sternotomy [in Japanese]. Nihon Kyobu Geka Gakkai Zasshi. 1990;38:1459-62.

12. Baisden CE, Greenwald LV, Symbas PN. Occult rib fractures and brachial plexus injury following median sternotomy for open-heart operations. Ann Thorac Surg. 1984;38:192.

13. Graham JG, Pye IF, McQueen IN. Brachial plexus injury after median sternotomy. J Neurol Neurosurg Psychiatry. 1981;44:621-5.

14. Vander Salm TJ, Cutler BS, Okike ON. Brachial plexus injury following median sternotomy: part II. J Thorac Cardiovasc Surg. 1982;83:914-7. 
15. Greenwald LV, Baisden CE, Symbas PN. Rib fractures in coronary bypass patients: radionuclide detection. Radiology. 1983;148:553-4.

16. Canbaz S, Turgut N, Halici U, Sunar H, Balci K, Duran E. Brachial plexus injury during open heart surgery: controlled prospective study. Thorac Cardiovasc Surg. 2005;53:295-9.

17. Bolotin G, Buckner GD, Jardine NJ, Kiefer AJ, Campbell NB, Kocherginsky $\mathrm{M}$, et al. A novel instrumented retractor to monitor tissuedisruptive forces during lateral thoracotomy. J Thorac Cardiovasc Surg. 2007;133:949-54.

18. Lederer W, Mair D, Rabl W, Baubin M. Frequency of rib and sternum fractures associated with out-of-hospital cardiopulmonary resuscitation is underestimated by conventional chest X-ray. Resuscitation. 2004;60:157-62.

19. Bauer M, Pasic M, Ewert R, Hetzer R. Ministernotomy versus complete sternotomy for coronary bypass operations: no difference in postoperative pulmonary function. J Thorac Cardiovasc Surg. 2001;121:702-7.

20. Brown ML, McKellar SH, Sundt TM, Schaff HV. Ministernotomy versus conventional sternotomy for aortic valve replacement: a systematic review and meta-analysis. J Thorac Cardiovasc Surg. 2009;137:670-9.

21. Moreno-Cabral RJ. Mini-T sternotomy for cardiac operations. J Thorac Cardiovasc Surg. 1997;113:810-1.

22. Rogers CA, Pike K, Angelini GD, Reeves BC, Glauber M, Ferrarini M, et al. An open randomized controlled trial of median sternotomy versus anterolateral left thoracotomy on morbidity and health care resource use in patients having off-pump coronary artery bypass surgery: the Sternotomy Versus Thoracotomy (STET) trial. J Thorac Cardiovasc Surg. 2013;146: 306-16.e9.

23. Kalso E, Mennander S, Tasmuth T, Nilsson E. Chronic post-sternotomy pain. Acta Anaesthesiol Scand. 2001;45:935-9.
24. Meyerson J, Thelin S, Gordh T, Karlsten R. The incidence of chronic post-sternotomy pain after cardiac surgery: a prospective study. Acta Anaesthesiol Scand. 2001;45:940-4.

25. King KM, Parry M, Southern D, Tsuyuki RT. 1359: Women's Recovery from Sternotomy-Extension (WREST-E) Study: examining long-term pain and discomfort following sternotomy and their predictors. Eur J Cardiovasc Nurs. 2008;7(suppl):S34-5.

26. Woodring JH, Royer JM, Todd EP. Upper rib fractures following median sternotomy. Ann Thorac Surg. 1985;39:355.

27. Gumbs RV, Peniston RL, Nabhani HA, Henry LJ. Rib fractures complicating median sternotomy. Ann Thorac Surg. 1991;51:952.

28. Vahl CF, Carl I, Müller-Vahl H, Struck E. Brachial plexus injury after cardiac surgery: the role of internal mammary artery preparation: a prospective study on 1000 consecutive patients. J Thorac Cardiovasc Surg. 1991;102:724-9.

29. Tomlinson DL, Hirsch IA, Kodali SV, Slogoff S. Protecting the brachial plexus during median sternotomy. J Thorac Cardiovasc Surg. 1987;94:297-301.

30. Healey S, O'Neill B, Bilal H, Waterworth P. Does retraction of the sternum during median sternotomy result in brachial plexus injuries? Interact Cardiovasc Thorac Surg. 2013;17:151-7.

31. Unlü Y, Velioğlu Y, Koçak H, Becit N, Ceviz M. Brachial plexus injury following median sternotomy. Interact Cardiovasc Thorac Surg. 2007;6:235-7.

32. Vander Salm TJ, Cereda JM, Cutler BS. Brachial plexus injury following median sternotomy. J Thorac Cardiovasc Surg. 1980;80:447-52.

33. Robicsek F, Fokin A, Cook J, Bhatia D. Sternal instability after midline sternotomy. Thorac Cardiovasc Surg. 2000;48:1-8.

34. Fokin AA, Robicsek F, Fokin A, Anderson JE. Changes in sternal blood flow after different methods of internal thoracic artery harvesting. Thorac Cardiovasc Surg. 2004:52:334-7. 